\author{
March 7-9, 2019 , London-United Kingdom
}

\title{
Consequences of Contract Labour System on Team Dynamics in India
}

\author{
Mote Umeshkumar \\ Tata Memorial center - ACTREC, Mumbai, India
}

\begin{abstract}
Maximum organizations have two categories of Human resource i.e. Permanent and Contract (outsourced). The major basic difference in two is that their primary employers are different. Employer for permanent employees is organization itself and for contract employees respective contractor. However, the working place and organizational goal remains same for both. So it is obvious that a Team may consist both types of employees in an organization. The major aspects which may affect Team dynamics of such Teams is Job-security, Salary-structures, Welfare-benefits, Working-rules etc. Because of these differences there may be feeling of inferiority among the contract employees and superiority among the permanent employees or vice versa. The key intentions behind appointing contract employees essentially in an organization is to have flexibility in appointment, Cost cutting, minimize legal compliances. However, all above facts adversely affects the morale of individual contract employee and may directly affect optimistic Team building. To tackle and minimize above differences organizations may imbibe - Job-security- Appointment of contract employee shall be equivalent to the contract period of respective contract. Salary-Structure- If nature of work allocated to permanent employees and contract employees is same and similar; it is desirable to pay similar monthly emoluments. Welfare-facilitiesContract employees shall allowed to use basic welfare facilities viz. canteens, sports, cultural programs etc. along with permanent employees. Working-rules - Working hours, leave rules, weekly offs, safety rules etc. shall be similar for both type of employees.
\end{abstract}

Keywords: Contract, Permanent, Job-security,Salary-structures,Welfare-benefits, Working-rules Themes: To achieve the organization goals, it is very essential to minimize the gaps between contract employees and permanent employees. 